\title{
What Optimistic Responses to Deep Disagreement get Right (and Wrong)
}

Received: 10/09/2019 | Reviewed: 16/04/2020 | Accepted: 18/04/2020

DOI: 10.17230/co-herencia.17.32.8

\author{
Scott F. Aikin* \\ scott.f.aikin@vanderbilt.edu
}

\begin{abstract}
In this paper, I argue for three theses. First, that the problem of Deep Disagreement is usefully understood as an instance of the skeptical Problem of the Criterion. Second, there are structural similarities between proposed optimistic answers to deep disagreement and the problem of the criterion. Third, in light of these similarities, there are both good and bad consequences for proposed solutions to the problem of deep disagreement.
\end{abstract}

\section{Keywords:}

Deep disagreement, skepticism, problem of the criterion, argumentation.

\section{Qué respuestas optimistas al desacuerdo profundo generan buenos (y malos) efectos}

Resumen El presente artículo presenta tres tesis. En primer lugar, plantea que el problema del desacuerdo profundo se entiende, convenientemente, como un ejemplo del problema del criterio desde la óptica del escepticismo. En segundo lugar, existen similitudes estructurales entre las respuestas optimistas que se proponen con respecto al desacuerdo profundo y al problema del criterio. Y, en tercer lugar, ante dichas similitudes, las soluciones que se proponen frente al problema del desacuerdo profundo generan tanto buenas como malas consecuencias.

\section{Palabras clave:}

Desacuerdo profundo, escepticismo, problema del criterio, argumentación.

\author{
Assistant Professor \\ of Philosophy and \\ Director of Under- \\ graduate Studies at \\ Vanderbilt Univer- \\ sity, USA. ORCID: \\ 0000-0002-5358-7234
}


The fact of disagreement is inescapable in social life. Who would deny it (and thereby disagree)? Some disagreements are tractable and even resolvable, but others are long-standing, wide-ranging, and seem irresolvable. The challenge of these disagreements of significant depth is that of identifying what rational procedure generally, and what tool of argument specifically, can break the logjam. Despite the fact that the special technical notion of deep disagreements has been around only since Robert Fogelin's 1985 essay, the form of the problem has been at work in the longstanding skeptical Problem of the Criterion since its statement in the late ancient period in Sextus Empiricus's Outlines of Pyrrhonism. I think it is instructive to view the problem of deep disagreement as an instance of the problem of the criterion, and so I will lay out the structural similarities between the two problems and turn then to show why this analogy is useful. In particular, the isomorphism between the two problems pays off when evaluating proposed solutions to the problems.

The problem of the criterion admits of two broad classes of solution, aptly identified by Roderick Chisholm (1973) as Particularism and Methodism. Both forms of solution have their own appeal, but both suffer from the same structural epistemic problem: they beg the question, and so do not fully answer the challenge of the problem of the criterion. The same, as I see it, goes for optimistic replies to the problem of deep disagreement. (For the distinction between optimistic and pessimistic solutions, see Aikin, 2019; and Godden \& Brenner, 2010). The optimistic solutions I will survey are Peter Davson-Galle's "primitive epistemic assent" (1992, p. 150) and Vesel Memedi's "third party" mediators (2007, p. 5). In both cases, there are appealing features to the optimistic replies, but here are significant drawbacks to them as replies, too. Particularly, that they, like their cousins purportedly solving the problem of the criterion, beg the question, given the description of what deep disagreements are.

\section{The Problem of the Criterion}

The problem of the criterion is an ancient skeptical trope that can be posed with the following challenge: how can we sort true from 
false propositions, without presuming we have already sorted them appropriately? Here's how the challenge works, as the presumption is revealed with the following circle of reasons, or more evocatively termed by the Pyrrhonists, the wheel (diallelus):

Q1: How do I know if these propositions (or presentations) are true (or false)?

A1: Because they are assigned a value by a reliable or good criterion.

Q2: How do I identify a good or reliable criterion?

A2: A good or reliable criterion correctly sorts true from false propositions.

The problem is that in order to give A2, we must have answered Q1, which begins the series of questions and answers all over again. Hence, we see the wheel of critical reflection that constitutes the problem of the criterion. As Sextus Empiricus states the matter:

[I]n order to decide the dispute which has arisen about the criterion, we must possess an accepted criterion by which we shall be able to judge the dispute; and in order to possess an accepted criterion, the dispute about the criterion must first be decided (PH, II.20).

Roderick Chisholm, in his 1973 Aquinas Lecture, The Problem of the Criterion, comments on the history and structure of the problem:

And now, you see, we are on the wheel. First we want to find out which are the good beliefs and which are the bad ones. To find this out, we have to have some way -some method- of deciding which ones are the good ones and which are the bad ones. But there are good and bad methods [...] And so we now have a new problem: How are we to decide which are the good methods and which are the bad ones? (1973, p. 10).

The basic structure of the problem is that one must procedurally have two things before each other -one must possess the truths to identify criteria and criteria to possess truths. And without one or the other, one has neither. (See Amico 1993, p. 93; Cling 2014, p. 165; and Aikin, 2018a on the structure of the problem of the criterion being one of a conflict between what must be epistemically prior).

Solutions to the problem of the criterion generally come in two forms -either one starts with a set of truths and generates the criteria for truth from what these truths share in common, or one begins 
with criteria and generates truths from their application. That is, given the two critical questions and two answers (Q1 and A1, or Q2 and A2), one could start with either complex. Chisholm (1973) identifies the set of questions as two pairs of questions:

(A) "What do we know? What is the extent of our knowledge?"

(B) "How are we to decide whether we know? What are the criteria for knowledge? (p. 12).

The solutions, or better, approaches, to the Problem of the Criterion are to answer one of the question-complexes first, and then turn to answering the other in light of how one had answered the first. Chisholm dubs the two strategies 'Methodists', who begin with questions of criteria, and 'Particularlists', who being with the question of instances.

I suggest, for the moment, we use the expressions "Methodists" and "Particularists". By "Methodists", I mean [...] those who think they have an answer to B, and who then, in terms of it, work out their answer to A. And by "Particularists" I mean those who have it the other way around (1973, p. 15).

Methodism comes in many forms in epistemology. Empiricism, for example, is a form of Methodism -experience provides us with truths, it is our criterion. Rationalism, too, is a form of Methodism, as the dictates of reason serve as the condition for accepting a content as true. Particularism, beginning with a set of truisms, is strongly associated with Common Sense traditions. One has a raft of commitments that have primarily the common thread that, to begin, is the simple fact that they are dictates of common sense they are the kinds of things that strike us as silly or even absurd to doubt. One then designs the rules for reasoning and our criteria for knowledge around these obvious cases.

The trouble, of course, is that these strategies break the rule set forth with the initial statement of the challenge of identifying a criterion and its associated truths -we must do so without presuming that we already have an answer. We must do so without begging the question. If truths and criteria for truths are mutually epistemically prior to each other, then beginning with either will be epistemically out of order. Chisholm, in stating the options as he has (and even in stating his case for Particularism) concedes that: 
What few philosophers have had is the courage to recognize is this: We can deal with the problem only by begging the question. It seems to me that, if we do recognize this fact, as we should, then it is unseemly for us to pretend that it isn't so (1973, p. 37, emphasis added).

The lesson, as I take it, is that solutions to the problem of the criterion are less means of showing that the problem is not a problem but more ways of managing the problem. In the case of Methodism and Particularism, the answers to the challenge beg the question, and so are not solutions, given the structure of the problem, but they are ways forward for other programs of cognitive management, such as making one's beliefs more systematic and consistent. But, again, because of the problem of begging the question, they do not solve the problem of the criterion.

\section{Deep Disagreements}

A useful strategy for articulating what deep disagreements are is to start with a contrast. Normal disagreements are those wherein the two disagreeing parties nevertheless agree on some background matters -in particular, they agree on some broad set of propositions bearing on the item of disagreement and they share a number of salient epistemic resources. So, though two people may disagree, following Fogelin's famous examples, about the best path for their errands, if they agree about the geography and traffic patterns of the city, their disagreement is normal and so tractable. And if two people disagree about who was the batting champion in the baseball league for a particular year, if they agree that looking up the answer in the league's book of records will settle the matter, then they have a normal and tractable disagreement. In short, normal disagreements are those wherein the disagreeing parties share enough in common that an argument can, in principle, resolve the issue. For sure, it's still possible for a party to remain a holdout against the prevailing reasons, but this is a different kind of problem from deep disagreements.

When disagreements are deep, the parties do not share the relevant background commitments that allow simple reasoning to resolution. Nor do they share deference to the same epistemic 
resources. In cases of deep disagreement, the parties share no overlapping commitments or resources. Fogelin holds that, consequently, argument is not possible in these instances. He reasons that "the possibility of a genuine argumentative exchange depends ... on the fact that we together share many things" (1985, p. 6). In turn, since those things are not shared in deep disagreements, the disagreements "cannot be resolved through the use of argument, for they undercut the conditions essential to arguing" $(1985$, p. 8).

The analogy between the problem of the criterion and that of deep disagreement should be clear. The background procedural rule for deep disagreement is what I have elsewhere termed the requirement of dialecticality, namely that a premise or resource must be acceptable to one's interlocutor for it to play a legitimately resolving role in an argument (Aikin, 2018b, p. 175, and 2018a). It is analogous to the rule of support for epistemically prior commitments for the problem of the criterion -if one's justifying reasons depend on an unjustified commitment or step, then everything downstream from that unjustified component is undercut.

Given the structural similarity between the problem of the criterion and deep disagreements, the classes of proposed solutions to deep disagreements will have similar problems of question-begging that those to the problem of the criterion had. Methodist solutions to the problem of the criterion start with sources of or procedures for producing commitments. But, as we'd seen with how deep disagreements are described, there are no shared salient cognitive resources. So Methodist programs with deep disagreements cannot, given the structure of the problem, be solutions. And the same goes for Particularist solutions -finding sets of truisms from which to begin is a hopeless task for deep disagreements, since, by hypothesis, there are none in contexts of deep disagreement.

\section{Davson-Galle and Primitive Epistemic Assent}

Peter Davson-Galle's 1992 essay, "Arguing, Arguments, and Deep Disagreements" has two theses. The first is that Fogelin's irresolvability thesis is defensible against Andrew Lugg's 1986 criticism that a practical perspective on argument resolves deep 
disagreements. Lugg's argument was that, in essence, the overlap of commitments required for resolving disagreements is itself a product of argument, instead of a precondition for it. The details of Davson-Galle's defense need not detain us here, since the target for evaluation is his second thesis, that "rational persuasion might be more powerful in other ways that Fogelin allows" (1992, p. 154). So, though Fogelin's argumentative pessimism is defensible against one critical challenge from Lugg, it is open to a different form of optimistic challenge.

Davson-Galle pursues two lines of argument to substantiate the second thesis. The first is a negative line -that one can "rationally persuade someone of the error of his/her ways by tracing distasteful consequences [...] One is, so to speak, pointing out an inconsistency in the set of propositions s/he subscribes to" (1992, p. 154). This negative line establishes that something's gone wrong, but not what the fix is.

The second line of argument Davson-Galle pursues is to note that there are instances of "primitive epistemic assent" around which arguments occur and from which they may begin. And further, they may be events that bring arguments to abrupt ends. Davson-Galle explains what these acts entail with a disagreement between a hypothetical Jack and Jill:

What can Jack to? He might be able to create conditions for an act of primitive epistemic assent somehow; that is, create circumstances in which a proposition is warranted to/by Jill, but not in virtue of any argument or the provision of reasons (1992, p. 150).

The thought is that there are other ways we change our minds about things other than being on the receiving end of arguments from others. We may reflect, or feel, or have experiences. Any of these non-argumentative cognitive moments can produce a change in view and thereby a resolution. Davson-Galle provides an explanation for how this happens:

It might be construed as akin to conversion [...] or it might be construed as akin to persuading someone to accept it's raining by opening a blind so that he can see that it is so. Either way [...] what one is doing is putting the other cognitive agent into a situation where a primitive epistemic assent occurs: assent is given without reasons for the assent (1992, p. 150). 
The key, Davson-Galle holds, is that Fogelin's model for deep disagreements depends too much on antecedent acceptances for rational resolutions -one can use primitive epistemic resources to resolve disputes that need no background acceptances. (Along these lines, Wang 2018 argues that non-argumentative strategies are the only way forward at this stage).

It is clear that Davson-Galle's solution to the problem of deep disagreement is a form of Methodism -that two methods may be used for resolution- finding internal contradictions and inducing primitive epistemic assents. Davson-Galle concedes that the former has significant limitations in that it, again, does not propose a truth on the other side of the inconsistency, and it also depends on one's interlocutor sharing some "canons of logic" (1992, p. 154). The latter, however, Davson-Galle seems to hold has limits only as far as what can be primitively epistemically presented.

First, it is worth noting that what Davson-Galle's proposal has done is significantly shrink the domain of what can count as deep disagreements. If, by hypothesis, the disputants do not share either salient commitments or cognitive resources in deep disagreements, then finding instances of resolutions consequent of discovered internal contradictions or primitive epistemic assents is also finding instances that are not deep disagreements. That does not mean that they are not resolutions, but it does mean that they are not resolutions to deep disagreements.

The crucial insight is that if the disagreements are deep in the way that Fogelin's program has stipulated, then it is not just a nonoverlap of commitments but epistemic resources, too, for resolution. So internal reductio depends on shared resources for deriving the contradiction, and so also does primitive epistemic assent. Given the demands of deep disagreements, these resolutions, if successful in these fashions, demonstrate the disagreement is not deep. And if the disagreement is truly deep, these strategies will, given the dialiecticality requirement, beg the question. 


\section{Memedi and Third-Party Mediation}

Vesel Memedi argues in "Resolving Deep Disagreement" that at least some deep disagreements "can be rationally resolved by introducing the concept of 'third party' to those particular discourses" (2007, p. 1). Memedi's primary example is that of the conflict between Macedonian governmental forces and Albanian armed groups living in Macedonia in 2001. The narratives of the conflict's history and what the respective sides are trying to accomplish varied greatly between the two parties. The Macedonians accused the Albanians of trying to create, as Memedi reports, "a 'Greater Albanian' state," but the Albanians reported their motives only as to attain "greater rights for Albanians in Macedonia" (2007, p. 6). When the debate proceeded along these lines, Memedi holds, there was an incommensurability of reasons, and so an argumentative impasse.

The crucial element to Memdi's case study was a third party to the critical discussion. Memedi observes that the audience the two primary disagreeing sides appealed to was one outside the debate:

[T] here is a presence of another audience that I think plays a crucial role in reconstructing better the discussion between Madedonian and Albanian language media. This role is played by 'the international community' (2007, p. 7).

The upshot is that the way to break the logjam of the deep disagreement, Memedi reasons, is to find a judge incorporated into the discourse. Memedi's two criteria for these third party judges are that (1) they must be "capable of being influenced," and (2) they must "have the capability to act as "mediators of change", and in particular, this agency means that they are "more powerful" than the sides being mediated (2007, p. 9).

One question, of course, is how the fact that the mediator is more powerful than the singular parties is relevant to the rational resolution to the debate. That one party can convince a stronger party to take their side does not count as any more rational a resolution than that he party has stronger allies or that one party is itself simply stronger than the opposition. I presume that the issue of identifying stronger parties as mediators is an acknowledgement 
of the realism of disagreements -that rational resolution is by itself not sufficient for lasting resolutions, but some plausible threat of sanctions is required too. Regardless, the important element to Memedi's third party mediator is implicit, at least in the case study of the Albanian-Macedonian conflict, namely that both parties to the dispute argumentatively appeal to the same third party. That is, despite the apparent depth of the disagreement between the two parties, they agree on a mediating source of resolution.

It is not difficult to see Memedi's program as a form of deep disagreement Methodism -as Davson-Galle's program had been earlier-one that proposes a procedure for producing resolving reasons for the dispute. The problem, as seen before, is that if the sides do agree on the mediating party, then they share a cognitive resource, and so do not have a deep disagreement, properly described. If they are deeply disagreeing, then they will not have a mutually agreed upon mediator.

Seeing deep disagreement as an instance of the problem of the criterion is useful in this regard, since the mediator strategy is one of the methods the ancients had considered when addressing the problem of the criterion. Sextus Empiricus went out of his way to argue that it begs the question given the structure of the problem. "[S]ince there exists great difference among men, let the dogmatists first agree together that this is the particular man to whom we must attend, and then and only then, let them bid us also to yield him our assent [...] For if they declare that we must believe the sage, we shall ask them, 'what sage?' [...] [T]hey will be unable to return us a unanimous answer" ( $\mathrm{PH}, \mathrm{II} .38)$. And so, insofar as there is first-order deep disagreement about the facts of the case, there will be secondorder disagreement about who is the right resource for accurate judgment. Again there may be agreement about who is the strongest and who can most effectively enforce a decision, but this is not the challenge of the criterion or of deep disagreement.

Memedi qualifies his solution to the problem of deep disagreement by noting that the third-party mediation strategy is highly contingent, so his conclusion is "modest" (2007, p. 10). His qualification is that his solution is indexed only to cases where there is a deep disagreement and the two parties address a moveable and 
stronger third party. Only under those conditions is there hope for this kind of rational resolution to deep disagreements. The results of the case study are not universal for deep disagreement, but are restricted to these conditions. "There is no intention on my part to generalize these two criteria to other types of discourse," Memedi clarifies (2007, p. 9).

\section{The Good News and the Bad News}

Let me start with the good news. What optimistic programs with deep disagreement, those on analogy with the problem of the criterion with formally Methodist approaches in particular, get right is that there are many ways that what look initially like deep disagreements are, in fact, not absolutely deep disagreements. To appreciate this point, a distinction is in order. Depth is a gradable concept, so disagreements may be of various depths, some more deep than others (see Aikin, 2019; Duran, 2016; and Wang, 2018). Disagreements are deeper in terms of how many dialectical steps must be traversed to address the issue, and those that are absolutely deep have no upper limit on the steps necessary. So with some disagreements, only one argument is necessary, and with others, many back-and-forths are required. The former are not deep at all, and the latter are of degreed depth. But, again, given Fogelin's description of deep disagreement, there are others without any number of steps to get to resolution -any given argument will occasion more challenges. And so, with these, we are thrown upon the skeptic's wheel.

What deep disagreement optimism gets right, then, is that there are instances wherein we have disagreements of depth, but we may yet find new, unanticipated, epistemic and argumentative resources that contribute to the resolution of the dispute. In Davson-Galle's case, 'primitive epistemic assent' is a shared cognitive resource that can break the logjam of conflicting reasons. But, if we can do this and appeal to these sources of belief, it shows that though the disagreement may have depth, it is not absolutely deep. The same goes for Memedi's program of third-party mediation. The disagreement on the first level may be deep in that when the parties address each 
other, they cannot provide any reasons that meet the requirements of dialecticality. But if they happen to share regard for a third party to judge the dispute, they in turn have a shared cognitive resource. And so, though the dispute has a degree of depth, it is not absolutely deep.

Consequently, the good news is that optimistic programs with deep disagreement give us hope and methods for proceeding in the face of what often seems to be deep disagreement. The hope is that not all disagreements that are deep are absolutely deep, and the methods provided are those of revealing ways forward in cases wherein we think we face a deep disagreement.

The bad news is that these are not solutions to the problem of deep disagreement, so described. If the disagreements are deep, or as I've termed them for clarity's sake with the gradable concept of depth, absolutely deep, then these solutions will share the same problem that all Methodist solutions to the problem of the criterion have had -they will beg the question, and so are not really solutions.

What deep disagreement optimism of this particular Methodist form amounts to, then, is a program of showing that the domain of deep disagreement recedes when we apply our critical skills to the disagreements before us. Argument's reach is broader than the pessimistic view that many who read Fogelin take -disagreements may be of depth, but there are many ways that we may nevertheless get to the bottom of things in them. What deep disagreement optimisms, at least of the form evaluated here, get wrong, however, is that these are not solutions to the problem of deep disagreement. This is because conditions for optimism identified in them are conditions that simply don't obtain in instances of deep disagreement, properly described. The problem, as I take it, has a particular dialogical structure, and given that structure, the approaches proposed cannot be rationally satisfactory solutions. If the conditions do obtain, then the optimistic views are about disagreements that are not absolutely deep. Thereby, they are not solutions to the problem of deep disagreement, but more incremental restrictions of the domain for the problem.

In a way, this conclusion should be a happy one for both deep disagreement optimists and for deep disagreement pessimists. The pessimists are right that the problem, properly described, is 
rationally insoluble in ways analogous to the longstanding skeptical challenge of the problem of the criterion. But the result is also happy for the optimists, because we see the extension of the domain for deep disagreements shrink. What loomed as a worrisome global problem for argumentation is by piecemeal theoretical work, being progressively pushed back. And this occasions a question: are there any really absolutely deep disagreements? And if they are really only theoretical possibilities, not regular and inescapable social realities, does it matter?

\section{References}

Aikin, S. (2018a). Deep Disagreement and the Problem of the Criterion. Topoi. https://doi.org/10.1007/s11245-018-9568-y

Aikin, S. (2018b). Dialecticality and Deep Disagreement. Symposion, 5(2), 173-179. https://bit.ly/2xI4oOX

Aikin, S. (2019). Deep Disagreement, the Dark Enlightenment, and the Rhetoric of the Red Pill. The Journal of Applied Philosophy, 36(3), 420435. https://doi.org/10.1111/japp.12331

Amico, R. (1993). The Problem of the Criterion. Rowman \& Littlefield.

Chisholm, R. (1973). The Problem of the Criterion. Marquette University Press.

Cling, A. (2014). The Epistemic Regress Problem, The Problem of the Criterion, and the Value of Reasons. Metaphilosophy, 45(2), 161-171. https://doi.org/10.1111/meta.12073

Davson-Galle, P. (1992). Arguing, Arguments, and Deep Disagreements. Informal Logic, 14(2/3), 147-156. https://doi.org/10.22329/il.v14i2.2537

Duran, C. (2016). Levels of Depth in Deep Disagreement. OSSA Conference Archive, 109, 1-8. https://bit.ly/2XNNc5x

Fogelin, R. (1985). The Logic of Deep Disagreements. Informal Logic, 7(1), 3-11. https://doi.org/10.22329/il.v7i1.2696

Godden, D. M., \& Brenner, W. H. (2010). Wittgenstein and the Logic of Deep Disagreement. Universidad Diego Portales, Centro de Estudios de la Argumentación y el Razonamiento. 
Lugg, A. (1986). Deep Disagreement and Informal Logic: No Cause for Alarm. Informal Logic, 8(1), 47-51. https://doi.org/10.22329/il.v8i1.2680

Memedi, V. (2007). Resolving Deep Disagreement. OSSA Conference Archive, 108, 1-10. https://bit.ly/2VTSo51

Sextus Empiricus (1990). Outlines of Pyrrhonism (R. G. Bury, Trad.). Prometheus Books.

Wang, C. (2018). Beyond Argument: A Hegelian Approach to Deep Disagreement. Symposion, 5(2), 181-195. https://bit.ly/2zdVCc6 